\title{
DO MATERIAL AO ESPIRITUAL: UMA LEITURA DA “CHAMA" A PARTIR DE WALTER BENJAMIN ENTRE “PONTOS NODAIS" E “FARNEL” DO ARTISTA ARTUR SOUZA
}

\author{
Clayton Rodrigo da Fonsêca Marinho* \\ Imaculada Maria Guimarães Kangussu**
}

\section{Resumo}

A proposta de trabalho é realizar uma leitura da passagem entre as obras da exposição "Pontos Nodais" e "Farnel" do artista Artur Souza, tendo como condutor da leitura a ideia de "chama" a partir do filósofo judeu-alemão Walter Benjamin. Tencionando a busca de um "teor coisal" e "teor de verdade", a filosofia parece vacilar em tentar apreender essa chama alquímica e não necessariamente os elementos que a compõe.

Palavras-chave: Crítica. Walter Benjamin. Farnel. Afinidade. Pontos Nodais.

\begin{abstract}
The proposed work is to perform a reading of the passage between the works in the exhibition "Nodal Points" and "Farnel" by the artist Artur Souza, with the driver reading the idea of "flame" from the German-Jewish philosopher Walter Benjamin. Intending to search for a "factual content" and "truth content", the philosophy seems to waver in trying to grasp this alchemical flame and not necessarily the elements that compose it.
\end{abstract}

Keywords: Critical. Walter Benjamin. Farnel, Affinity. Pontos Nodais.

\section{APRESENTAÇÃO}

Afortunados os tempos para os quais o céu estrelado é o mapa dos caminhos transitáveis e a serem transitados, e cujos rumos a luz das estrelas ilumina. Tudo lhes é novo e no entanto familiar, aventuroso e no entanto próprio. $\mathrm{O}$ mundo é vasto, e no entanto é como a própria casa, pois o fogo que arde na alma é da mesma essência que as estrelas. (Georg Lukács, Teoria do Romance)

\footnotetext{
* Mestrado em Estética e Filosofia da Arte pela Universidade Federal de Ouro Preto (UFOP). Graduado em Artes Visuais pela Universidade Federal do Rio Grande do Norte (UFRN). E-mail: clayton_marinho12@ hotmail.com. ** Doutora em Filosofia pela Universidade Federal de Minas Gerais. Pós-doutorado na School of Arts and Science da New York University. Atualmente é Professora-Associada no Departamento de Filosofia da Universidade Federal de Ouro Preto (UFOP).
}

DIALEKTIKÉ, v. 1, novembro 2014, p. 66-80

Artigo submetido em setembro/2014 e aceito em outubro/2014 
Em sua Teoria do Romance, Lukács, recuperando Novalis, afirma que filosofia é nostalgia, "[e]is por que os tempos afortunados não têm filosofia" . A filosofia, portanto, nasce do estranhamento do homem perante um mundo que não mais possui conexão imediata. Agora, ele precisa criar um intermediário para tentar compreender o mundo. A arte foi, por muito tempo, considerada uma forma de interliga-se com esse mundo, um mundo de valor, um mundo da verdade. Walter Benjamin já ressalta isso na cultura grega, que durante um período como o Renascimento tentou-se recompor. Contudo, como nos diz o filósofo, não se é possível retornar a esse período anterior, uma espécie de "infância" da humanidade. Irremediavelmente, o copo de cristal foi quebrado - não havia nenhum Eduard para segurá-lo ${ }^{2}$. Assim, o que nos resta é juntar os fragmentos e reordená-los nesse mundo, cabendo ao filósofo e ao artista, definir sua “pasta de vidro" para isso. O que está em jogo aqui é a percepção dessa dolorosa separação do mundo, no qual o homem moderno se percebe como aquele para o qual as estrelas já não têm o que dizer, "o céu estrelado de Kant brilha agora somente na noite escura do puro conhecimento e não ilumina mais os caminhos de nenhum dos peregrinos solitários"3.

O que Benjamin tenta fazer é buscar a condição originária, o nome originário ${ }^{4}$, que tornará o homem novamente conectado diretamente com a natureza. No mesmo esteio, Giorgio Agamben, já em $O$ homem sem conteúdo, parece buscar o mesmo. Retomando o conceito de autenticidade, ou originalidade, de uma obra de arte, ele relembra que ser original, está mais relacionado com "estar próximo da origem" do que ser único, portanto, condição para que se mantivesse sua aura. Mais do que essa proposição que o leva a colocar-se contra a proposição de Benjamin, de que a reprodutibilidade técnica não acabou com a aura, mas a multiplicou, o que se precisa ter em mente é a relação da obra de arte com a sua origem. Agamben parece usar essa retomada filológica do conceito como o meio para dizer que a obra de arte é, ainda, a forma mais próxima da origem, qual seja, daquela em que o homem não se estranhava com o mundo, no tempo em que não havia nostalgia. Contudo, o filósofo italiano precisa lidar com uma arte que está revestida da Estética, de um olhar filosófico sobre a obra de arte, que impregna toda nossa forma de percepção da arte, na busca por uma beleza. Isso é sintomático, na medida em que ele procura em Nietzsche um desvio. Na leitura que faz de Nietzsche, a Estética é delegada como a forma de percepção do espectador. Contra isso, levanta-se a visão do artista, do criador

\footnotetext{
${ }^{1}$ LUKÁCS, 2007, p.26.

${ }^{2}$ BENJAMIN, 2009.

${ }^{3}$ LUKÁCS, 2007, p.34.

${ }^{4}$ BENJAMIN, 1992.
}

DIALEKTIKÉ, v. 1, novembro 2014, p. 66-80

Artigo submetido em setembro/2014 e aceito em outubro/2014 
da obra de arte, e que, enquanto cria, não possui olhar estético sobre a obra de arte. Parece ser isso que Agamben tenta restaurar. Ao concluir que a obra de arte é um nada que se autonadifica, cria-se um campo desertificado, em que não se pode buscar nada além da própria autonadificação.

Apesar da negatividade que cerca essa obra, é preciso retomar Benjamin aqui, que já pressentindo algo parecido, quando, em Experiência e pobreza $a^{5}$, afirma que as pessoas estão mais pobres e perderam a capacidade de narrar após a primeira guerra mundial, chamando a atenção para a necessidade da instituição de um "conceito positivo de barbárie", , para o qual necessita-se de um caráter destrutivo ${ }^{7}$. Assim, em alguma medida, chegar à conclusão da autonadificação da obra de arte, Agamben parece colocar o caráter destrutivo, como ponto inicial da reconstrução de uma nova história, a partir do "começar do começo e de novo, sem olhar nem para a esquerda nem para a direita", a partir dos fragmentos da própria obra de arte. A arte produzida nas pós-modernidades parece se preocupar com isso, na medida em que ressalta as microestruturas, que possibilitam o realce de vozes antes excluídas e dão margem à fragmentação como forma de experimentação artística, tendo na constatação desse estranhamento do mundo a base líquida sobre a qual atuar. A experiência, nesse âmbito, constitui-se a partir da pobreza do fragmento, tendo-se em mente a flanêrie como o modus operandi dessa forma de construção da experiência, que parte do fragmento e já se percebe a impossibilidade de alcançar uma totalidade. Benjamin mostra isso no Prefácio críticoepistemológico em Origem do drama trágico alemão, quando percebe esse fragmento como participe da totalidade, criando uma espécie de desvio que proporcionará um vislumbre da verdade. O conceito torna-se o responsável por esse vislumbre, pois é ele que interliga o fenômeno à ideia, subvertendo a tese platônica, de modo que a ideia só tem importância porque sensibiliza-se no fenômeno, e este depende daquele para ser inteligível. Assim, o conceito é o intermédio, formando uma espécie de imagem dialética, já que guarda em si ambos. A partir disso, Benjamin conclui que ideia é mônada ${ }^{8}$ e deve se relacionar constelarmente com outras ideias, tendo na montagem o método possível. Desse modo, Benjamin mostra que o processo é tão importante para a filosofia quanto o resultado, pois, deve-se saber preparar a pasta de vidro

\footnotetext{
${ }^{5}$ Idem, 1986.

${ }^{6}$ Ibidem, p. 196.

${ }^{7}$ Ibidem, p. 187.

${ }^{8}$ Ibidem, 2011, p.35-36.
}

DIALEKTIKÉ, v. 1, novembro 2014, p. 66-80

Artigo submetido em setembro/2014 e aceito em outubro/2014 
que unirá essas ideias em busca do vislumbre da verdade, que se dará no deter-se sobre os fragmentos.

A arte conceitual parece responder a isso, mais de uma forma incompleta, pois enquanto a ideia prescinde do fenômeno para Benjamin, essa forma de arte considera que a ideia por si só já é a própria obra de arte. Não obstante, traindo-se a si mesmo, os artistas conceituais ainda precisam deixar algum rastro fenomênico, algum documento do processo da construção da obra. Assim, em vez da realização da obra, temos uma série de documentos do seu processo de construção sem, contudo, a possibilidade de realização. A arte contemporânea que se desenvolve nas pós-modernidades, nas quais se insere as obras a serem analisadas aqui, toma a mostra do processo como parte inerente à própria obra, de forma que sua inscrição na história da arte, nos discursos filosóficos e culturais torna-se um ponto importante, pois passase a demandar uma resposta à vida, quando os artistas mostram-se críticos da sua realidade. Apesar do afastamento que muito artistas desejam, seja como rejeição ao mercado da obra de arte, seja como forma de negação da interferência da realidade em sua produção, muitos conscientizam-se de que são corpos imersos no cotidiano e na história, e portanto, não fogem às suas demandas. De certa forma, vê-se uma politização da estética ${ }^{9}$, como já desejava Benjamin, ou melhor, uma politização da obra de arte. Mais do que isso, percebe-se a construção de um discurso crítico-reflexivo do próprio artista, fazendo-se a obra de arte, mesmo que vá para além de si, insira-se no debate como uma possibilidade. Escrever a história a contrapelo, como queria Benjamin, não se trata somente de revê-la do ponto de vista dos excluídos, mas, principalmente, de fazer notar que a transmissão ${ }^{10}$ é um processo ativo de escolha, de modo que o passado que foi interfere diretamente no presente que é, mas que poderia ter sido outro. Assim, faz-se notar que a ideia de origem (Ursprung) ${ }^{11}$ de Benjamin pode significar isto: um passado que se arrasta da sua gênese e atravessa o presente, em devir até o desaparecer. Nesse processo de devir, a transmissão tem papel fundamental na medida em que mantém o material próximo de sua origem ou o afasta. Existe, veladamente, um trabalho

\footnotetext{
${ }^{9}$ ibidem (1992, p.113).

${ }^{10}$ Aqui, concorda-se com a noção de Gagnebin (2008, p. 81), como um processo "histórico concreto, material, de desistências, de perseverança, de lutas e de violência que transporta ou não, leva ou não, transmite ou não um acontecimento ou uma obra do passado até nosso presente". Esse tipo de transmissão engendra-se numa constante atualização (Vergegenwärtigung), o que implica numa noção de cultura "[...] como relação espiritual viva do presente ao passado, do passado ao presente" (idem, p. 80).

${ }^{11}$ BENJAMIN, 2011, p.34.
}

DIALEKTIKÉ, v. 1, novembro 2014, p. 66-80

Artigo submetido em setembro/2014 e aceito em outubro/2014 
político aqui, ao qual a obra de arte não pode mais fugir. O artista com sua obra está, em alguma medida, fazendo política, quando seleciona aquilo que será transmitido pela história.

\section{PONTOS GRÁFICOS NODAIS NA CIDADE DO NATAL}

Anne Cauquelin, em $A$ arte Contemporânea ${ }^{12}$, elabora a ideia de rede, na qual se inscrevem as obras de arte, capaz de absorver tudo em que, uma vez interligada à rede, não se é mais possível sair. O grande problema dessa rede é a inexistência de um outro da rede, ou seja, de alteridade da rede. O que chama a atenção é justamente a colocação da obra de arte dentro dessa rede, que se utiliza da nomeação como forma de distinção da obra de arte, mas ao mesmo tempo, do mesmo. O nome cria a aparência de novidade dos objetos, quando constituem-se em nomes diferentes que designam as mesmas coisas. A rede necessita, em certo sentido inovar, movimentar-se, com a ilusão da novidade, mas ao mesmo tempo propaga-se da mesma forma. Entretanto, é interessante notar que o movimento aqui aparece como condição de manutenção da rede, e a obra de arte, constitui-se como um ponto nodal representante da rede. Ou seja, ela poderia se constituir como mônada da rede da arte contemporânea, pois guarda em si, na particularidade, virtualmente a totalidade da rede.

A primeira exposição da qual trataremos (realizada em 2011 como resultado do trabalho de conclusão da graduação do artista Artur Souza na Galeria do Deart e, posteriormente, na Pinacoteca do Estado, 2012, consistindo na exposição de uma série de gravuras expostas no chão, com dois vídeos - um das performances nas ruas da cidade, outro com a processo de impressão das gravuras), parece reivindicar essa postura de constituição monádica da rede, de forma que se apresenta como fragmento daquilo que a constitui, e graficamente, revela a propagação da rede, na forma de ecos. Isso ocorre em duas instâncias: material e gráfico. A obra constitui-se de gravuras, realizadas em pontos representativos da cidade, ruas e avenidas de importância que interligam a cidade do Natal/RN. Elas não têm a finalidade de representar a cidade, mas apresentam uma possibilidade de leitura; inscrevem-se no debate de outra possibilidade de cidade. Possibilidade essa engendrada justamente no fragmento, no ponto gráfico nodal, que (res)significa o espaço público, ao apresentar, pela interferência do equipamento de gravação e o deslocamento de seus usos, além do movimento da furadeira, uma outra possibilidade de experiência. As vivências urbanas, pela interferência

${ }^{12}$ CAUQUELiN (s/a).

DIALEKTIKÉ, v. 1, novembro 2014, p. 66-80

Artigo submetido em setembro/2014 e aceito em outubro/2014 
crítica do artista, podem, a partir de sua pobreza, constituir-se como experiência. Todavia, uma experiência fragmentária, pontual, configurando-se em certa medida, como um desvio que poderá dar possibilidade de vislumbre a alguma verdade.

No caso da obra, aquilo que aparece como a pasta de vidro, responsável por juntar os fragmentos e fazê-los significar é o corpo do artista. É importante ter em mente que as obras, como fragmentos, apresentações do fenômeno, sozinhos, sem a interferência ativa do artista, perdem sua possibilidade narrativa. O corpo do artista atravessa a obra como o ponto de interligação e sustentação. Tratando-se de uma proposta de gravura no campo expandido, no processo poético, a performance do artista e, como dispositivo original, o vídeo apresentam-se como os mecanismos de manifestação presente do atravessamento do corpo na obra. As performances deram-se em horário de pouquíssima movimentação, durante o intervalo do sinal de trânsito, próximas às faixas de pedestre. Outro momento do uso do vídeo, é o da documentação da preparação e impressão das obras, no ateliê do Departamento de Artes (Deart), na Universidade Federal do Rio Grande do Norte (UFRN). Como manifestação efêmera, sem o uso do vídeo para documentação, a obra ter-se-ia perdido nos fluxos da vida, como instante inscrito no silêncio da memória da história. A obra poderia existir tão somente como não existência, dentro de uma possibilidade de transmissão, que pouco sobreviveria na narração. $\mathrm{O}$ vídeo aparece como o documento que tenta preservar aquilo que não já não se consegue sustentar na narração. Ela não consegue se manter na tessitura da história, pois sua efemeridade (da performance realizada e dos corpos que a lembraria, seja pela presença no momento de execução ou pela narrativa do artista, na tentativa de rememorar a obra em seu todo) não permite. O vídeo surge como o ouvinte da narração, ou melhor como o autômato, que tenta guardar a vivência, para que significada na rememoração daquele evento, torne-se experiência. E, somente pelo vídeo, é que se percebe o atravessamento do corpo (como o realizador da performance e como o produtor das gravuras), que ativamente cria o percurso de apreciação da obra, ao vivamente exposto colocar-se como o fio que interliga os três momentos (performance, impressão, exposição).

DIALEKTIKÉ, v. 1, novembro 2014, p. 66-80

Artigo submetido em setembro/2014 e aceito em outubro/2014 


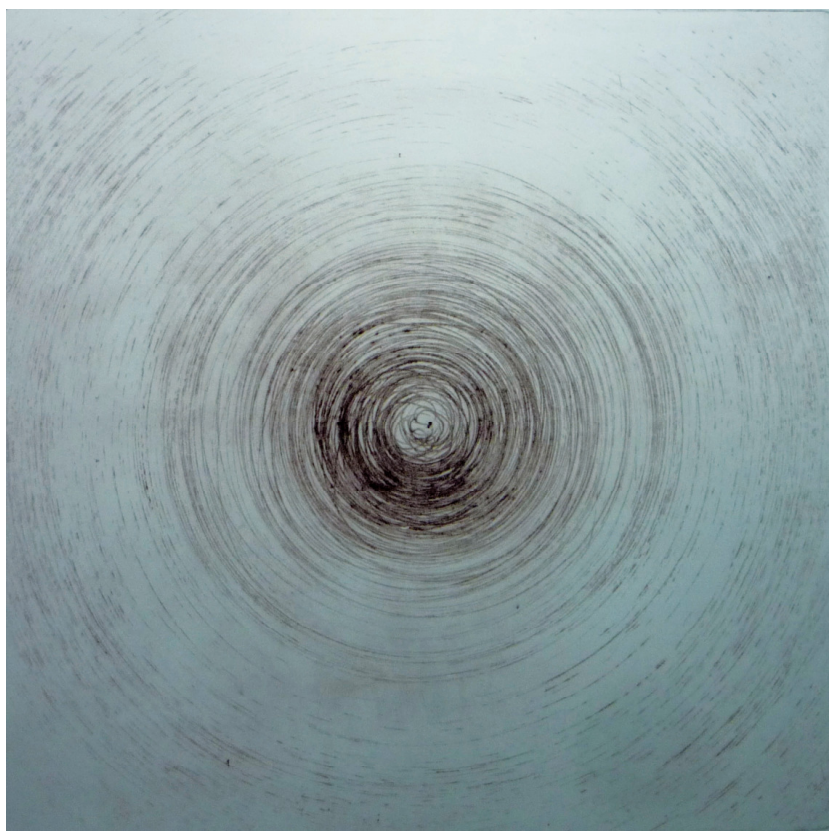

Figura 1: Gravura - avenida Afonso Pena. água-forte. Fonte: MACIEL (2011)

Assim como, para Benjamin, é o conceito que medeia a relação do fenômeno com a ideia, é o corpo do artista que medeia a relação entre a vida fragmentária e a obra de arte fragmentada. O corpo do artista intervém como o ponto nodal de transmissão. Ele é o responsável pela criação de fluxos que intervêm nos fixos ${ }^{13}$, configurando-se, fenomenologicamente, como o lugar de experiência da obra de arte. Nesse sentido, o corpo do artista, torna-se lugar de alteridade, na medida em que se coloca à disposição do outro (espectador) como ponto de reflexão da obra de arte. Apesar de, em seu trabalho, o artista somente mencionar uma única vez ${ }^{14}$ a alteridade, esta parece ser o ponto central da experiência em sua obra. Acredito estar aí a chama de sua obra. Ao colocar seu corpo como o modo de transmissão da obra de arte, este se constitui como o ponto fundamental da experiência do fragmento em sua obra. Seu corpo se dissolve, despindo-se do seu $e u$, e torna-se alteridade, torna-se conceito para o outro; é o elo entre a manifestação concreta da obra e a percepção de sua totalidade, do mosaico da arte contemporânea. O corpo do artista ecoa no outro como

13 “"...] fixos, estão fixados em cada lugar, permitem ações que modificam o próprio lugar, fluxos novos ou renovados que recriam as condições ambientais e as condições sociais e redefinem o lugar [...] fluxo são um resultado direto ou indireto das ações que atravessam ou se instalam nos fixos, modificando a sua significação e o seu valor, ao mesmo tempo [em] que, também, se modificam" (SANTOS apud MACIEL, 2011, p. 48-49).

${ }^{14}$ No capítulo "corpo", aparece no último parágrafo: “[...] corpo que marca e é marcado por sua ação. Esta ação também se caracteriza como uma investigação interior, mas que estabelece uma relação de alteridade entre indivíduo e sociedade" (MACIEL, 2011, p. 66).

DIALEKTIKÉ, v. 1, novembro 2014, p. 66-80

Artigo submetido em setembro/2014 e aceito em outubro/2014 
vivência da obra de arte, possibilitando a inscrição na experiência, porque justamente se torna ideia, essa mônada que guarda em si, fragmentariamente, a possibilidade da totalidade. A obra de arte corresponderia na rede da arte contemporânea, ao que o conceito corresponde na ideia. Inversamente, o corpo do artista, que não é coisa nem objeto, poderia constituir como o espaço de alteridade que a rede não possui. Ele é o espelho na casa fechada, que reflete as estrelas ${ }^{15}$.

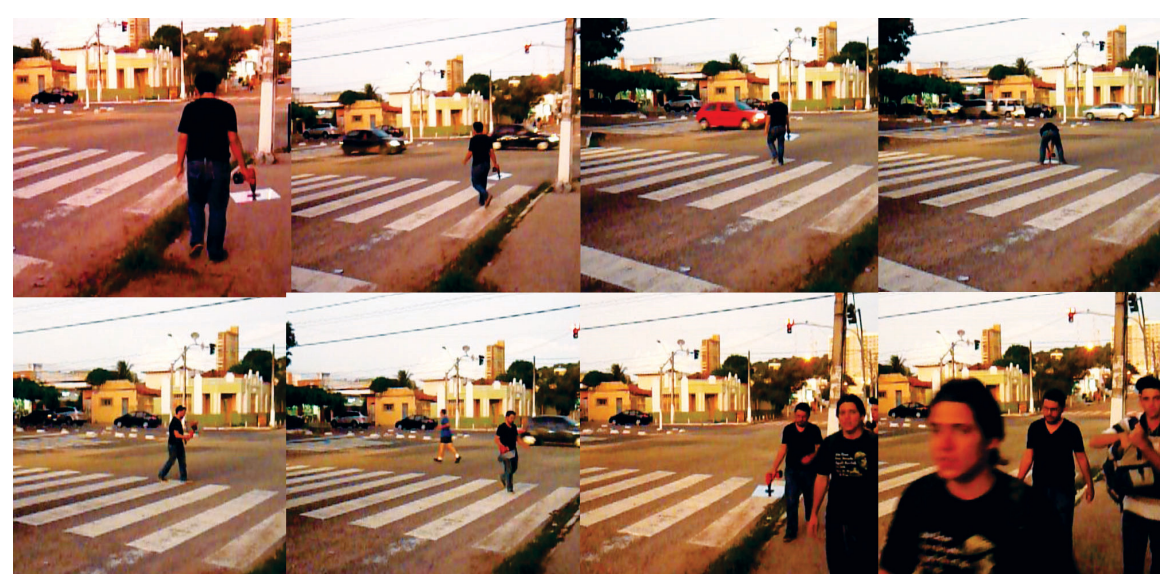

Figura 2: Frames do vídeo da performance na av. Afonso Pena Fonte: MACIEL (2011)

Nesse desvio que o corpo provoca, o que se aviva é possibilidade de alteridade que surge, mas como vislumbre. O outro (que está fora) torna-se, no seu processo de transmissão da história, a possibilidade de continuar vivendo (pela disposição das obras, o espectador deve se posicionar da mesma forma que o artista o fez para elaborar as chapas, posteriormente impressas). Somente através do outro é que a obra movimenta-se na rede e pode ser transmitida. Assim, como castigo para o artista, ele somente aparece como sujeito, na propagação do outro, no Eco. Mesmo que haja a intervenção do artista na disposição das obras, elas só se realizam como obras, no momento em que o espectador escolhe. O que antes era senhor de si, digno de ludibriar os deuses, criador par excellence, agora está à disposição do outro, para se constituir. No movimento cíclico, nesse espaço em que não se sabe o que está à frente nem atrás, de um ponto geram-se propagações para todos os lados, que se imiscuem com outras propagações e

\footnotetext{
15 "Por exemplo, uma janela noturna aberta, as duas persianas amarradas; um quarto sem ninguém dentro, apesar do ar estável que as persianas amarradas apresentam, e em uma noite feita de ausência e interrogação (esquecimento), sem móveis, a não ser o esboço plausível de vagas consoles, uma moldura, monstruosa e agonizante, de um espelho suspenso ao fundo, com sua reflexão, estelar e incompreensível, da grande Ursa (Ourse), que religa (relie) apenas ao céu essa morada abandonada do mundo" (MALLARMÉ apud MARTINS, 2011, p. 32-33). Em: MARTINS, Liana Carreira. "Do Azul ao Branco": Mallarmé e as construções da crise. Dissertação. Rio de Janeiro: UFRJ, 2011.
}

DIALEKTIKÉ, v. 1, novembro 2014, p. 66-80

Artigo submetido em setembro/2014 e aceito em outubro/2014 
fazem a rede se movimentar. O que permanece é a possibilidade de propagação do mesmo, do sempre igual. Contudo, agora inserindo a figura mítica da ninfa Eco, ainda existe um espaço para a liberdade: a escolha do que propagar, ou seja, a política ativa da transmissão. Todavia, Eco, da mesma forma que o artista, são condenados pela sua proximidade com a origem (uma da linguagem, o outro da obra de arte como apresentação do mundo) a constituir-se sujeito somente no outro, colocando a alteridade aqui não como condição essencial da vida, mas como necessária, pela qual se paga com a individualidade. A obra de arte é o único espaço possível, todavia, da manutenção de um equilíbrio entre ambos, pois mesmo que se transmita pelo outro, ainda guarda em si, como no conceito, o sujeito que a realizou, sempre próximo da origem.

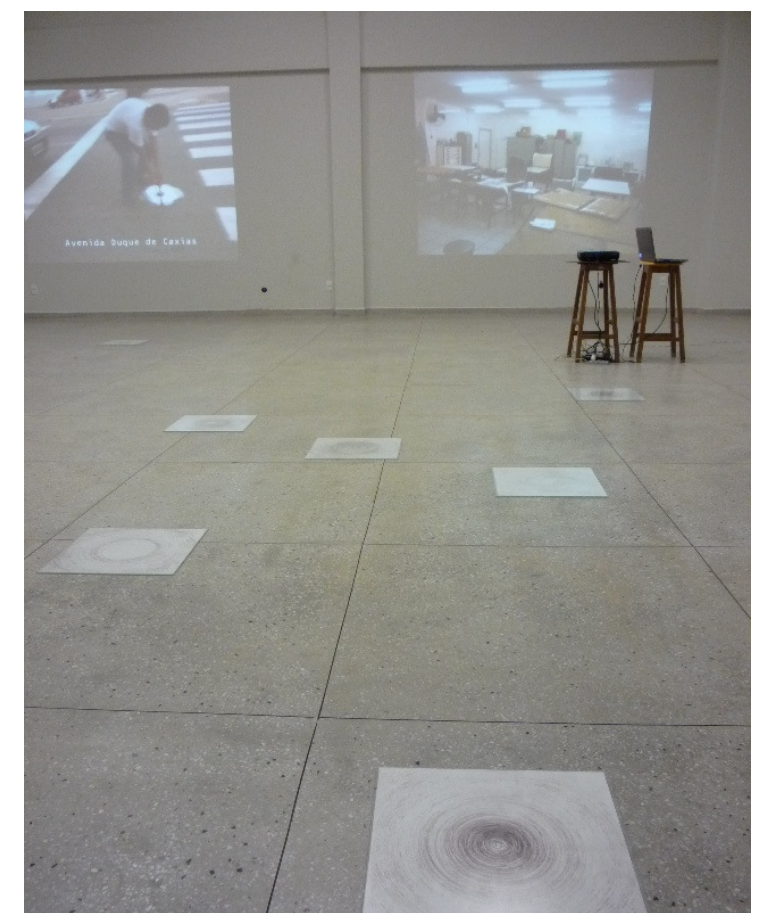

Figura 3: Exposição, deart, UFRN.

Fonte: MACIEL (2011)

\section{FARNEL}

A segunda exposição (ocorrida em 2013, na Galeria Conviv'Art da UFRN, resultado de experiências do artista desde 2009), tem como nomeação a comida enrolada em pano branco, muito comum dos nordestinos que iam trabalhar e levavam sua alimentação de casa, um antepassado da marmita. Como bem mostra o artista, Farnel serve de conceito aglutinante da série de pesquisas que elabora. É uma série de experimentações que se utiliza da aquarela e da queima de material, trabalhando com tintas e tecido, buscando um intermédio entre a 
transparência da aquarela e o negro do carvão. Água e fogo entram em sintonia de destruição, com o propósito da criação. O que se apresenta são os vestígios, as cinzas. Contudo, o que nos interessa aqui, é o momento entre o material e o imaterial, o instante em que se passa de um ao outro, e no entanto, não é ainda um ou outro, mas um $e$ outro. Mesmo que a ligação com a modernidade, Moris Louis e Yves Klein, a obra de arte não deixa de relacionar-se criticamente com o mundo. No passo em que se liga irremediavelmente à história, logo no processo ativo de transmissão, a obra não consegue fazer-se por si só. Ela se transforma num gesto situacional, localizado e aponta, ao mesmo tempo, para um futuro. Aqui, as obras parecem desejar uma aproximação da sua origem, constituindo-se como um momento de passagem.

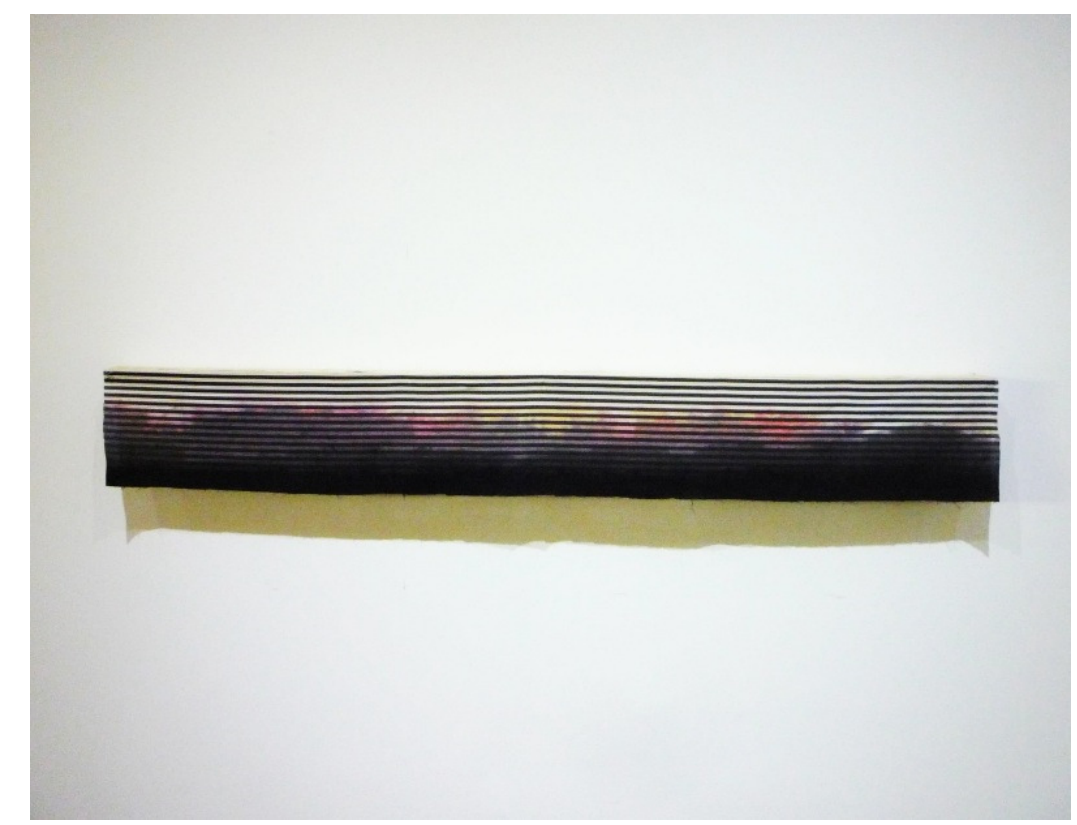

Figura 4: Farnel 1, 2012. tecido, madeira, pigmentos industriais, acrílica, carvão, alfinetes, douração. $18 \times 128 \mathrm{~cm}$.

O processo, ao contrário do que acontece com Pontos Gráficos Nodais tendo no corpo do artista sua imagem, encontra no fogo, mas do que na água da aquarela, a sua interligação. A aquarela se configuraria aqui, nesse intento, como a resposta do artista em tentar presentificar seu trabalho, para que sua contemplação fosse possível. Ela funciona como o elemento de cesura no tempo, como matéria que localiza a obra num espaço, na medida em que remedia sua destruição, executando a função do conceito, entre o fenômeno e a ideia. Com isso, Farnel parece um espaço de parada no tempo para um porvir, funcionando como o trabalho do artista em preparar a pasta de vidro, do próximo mosaico. Para isso, precisa desaparecer em seu devir, 
arrastar-se para frente, como o anjo melancólico de Paul Klee. Contudo, em vez de um vento que arrasta essa figura imortal pelo tempo, Farnel aparece como aquilo que é arrastado pelo tempo, porque é devir e está submetido a ele. Sua condição é a própria consumição. O fogo só é fogo enquanto se consome a si mesmo, na medida em que se consome. Mais do que refletir alguma coisa, ele ilumina. Logo, em vez de alteridade, configura-se como um eu narcísico, incapaz, pela própria natureza, surgida da violência, de reconhecer o outro. O espaço que a primeira abriu à alteridade na rede, o segundo se fecha, pela necessidade de desaparecer e engendrar a si mesmo, sustentar-se enquanto movimento. Uma é cesura, a outro movimento.

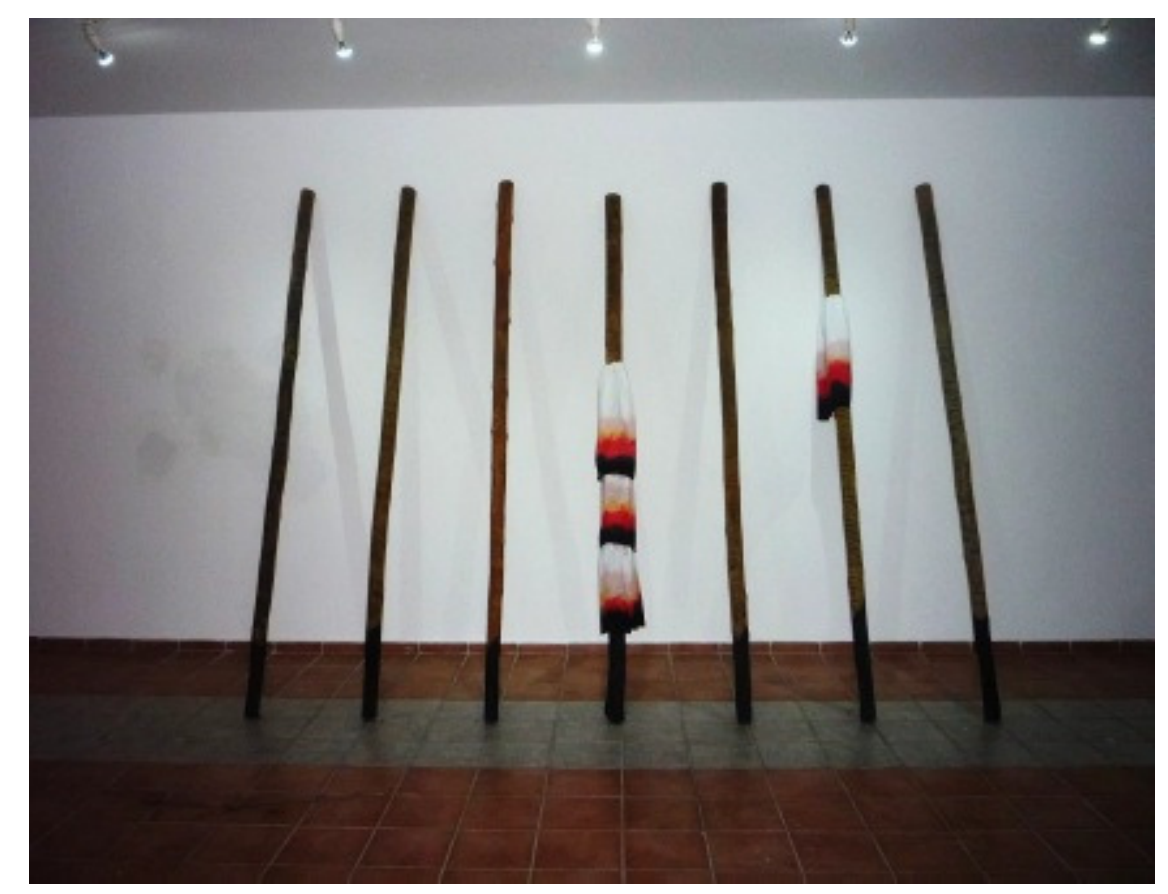

Figura 5: Farnel 5, 2012. tecido, estroncas de madeira, pigmentos industriais. $300 \times 400 \times 320 \mathrm{~cm}$ (aproximadamente).

Isso não significa, entretanto, que a obra não possua história. Em menor grau, ela se apresenta como vestígio, como risco. São as marcas das cinzas no material, nas estacas de madeira recostadas sobre a parede, que foram arrastadas (deixando suas marcas no chão da galeria), na queimadura dos tecidos e suas camadas de tinta, que apontam para um tempo originário (uma camada sobre outra), das bonecas queimadas, filmadas, que podem dizer sobre a infância, sobre sua perda. Esse afastamento, retomando Lukács, rememora a nostalgia, um plano em que a filosofia adentra para dar respostas ao mundo, mesmo que nunca as consiga 
responder. Como no Ptyx, em poema de Mallarmé ${ }^{16}$, talvez seja somente na duração da queima que o sentido exista. Logo após, o esquecimento ou a falta de sentido imperam, tornando a obra um resultado do sem-expressão. O que se percebe aqui é a impossibilidade de uma narração, pois o silêncio é o espaço para esse dizer. A única coisa que permanece é o movimento do desaparecer.

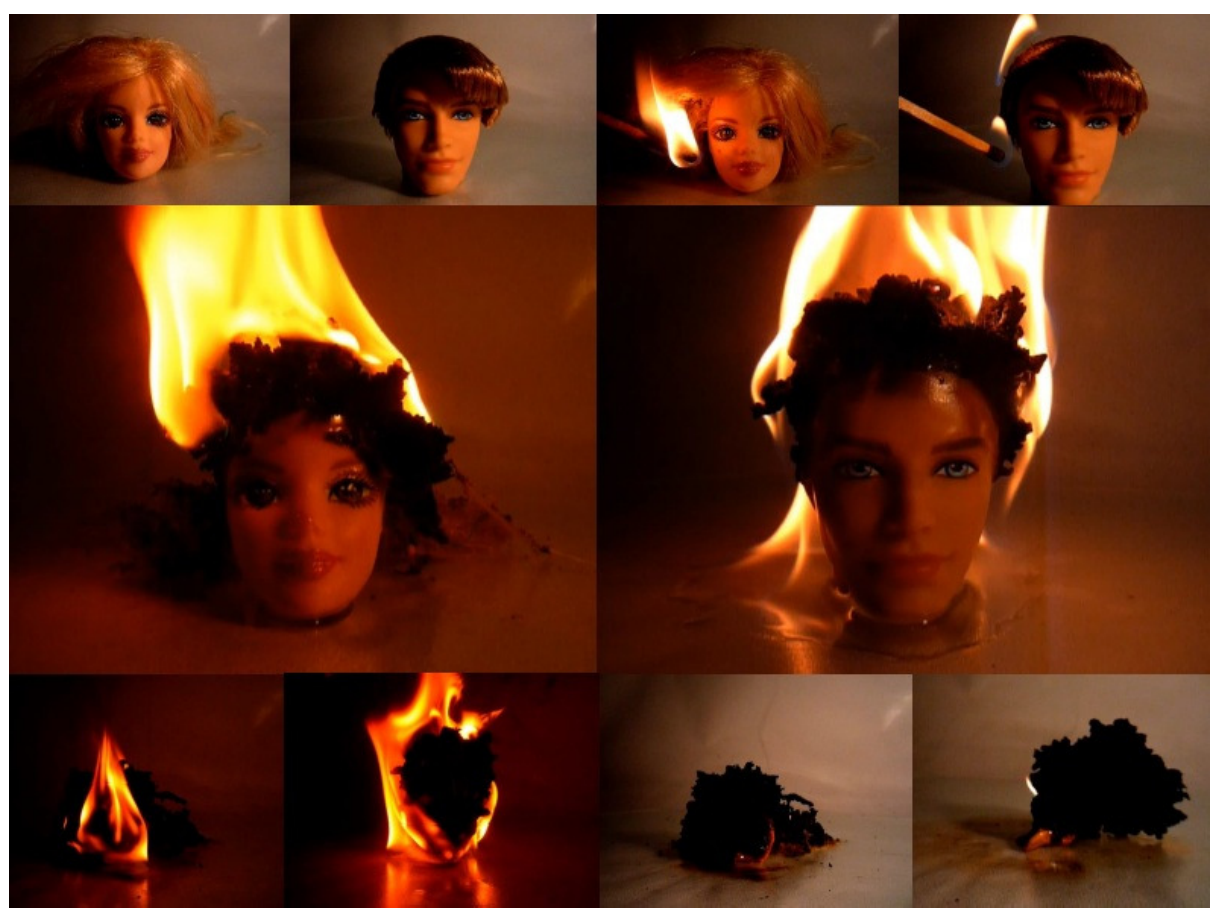

Figura 6: Frames do vídeo “Fiat Lux” (2012).

Esse movimento do desaparecer surge como um encantamento, convertendo “[...] o caos em mundo por um instante" ${ }^{17}$. Um instante, contudo, que não se permite dizer algo que não seja a si mesmo em movimento. É o sem-expressão, conforme Benjamin, que põe em movimento a aparência, ao qual se liga a obra de arte. Essa aparência apresenta-se ao mundo como o objeto velado. E ele só pode dizer algo sobre si, enquanto for o objeto velado, nem o objeto sob o véu, nem o próprio véu. Assim, aparece como vislumbre que se realiza no semexpressão, na cesura que não se pode desvelar, pois recairia numa inaparência. Dessa forma, enquanto Pontos Gráficos Nodais apresenta-se como alteridade ao espectador, ou seja, permitese como expressão pelo e no outro, Farnel só se realiza, como passagem, na medida em que

16 "Quero dizer, que o sentido, se nele existe um, [...] é evocado por uma miragem interna das próprias palavras" (MALLARMÉ apud MARTINS, 2011, p.32).

${ }^{17}$ BENJAMIN, 2009, p.91.

DIALEKTIKÉ, v. 1, novembro 2014, p. 66-80

Artigo submetido em setembro/2014 e aceito em outubro/2014 
não se deixa desvelar, impede o outro de construir uma experiência. Recupera-se, por assim dizer, o nada que nadifica a si mesmo, segundo Agamben. A obra aparece como Narciso, como aquele que só se possui como referência válida, que só se realiza consigo mesmo. Não é por acaso que o fim de Narciso deve ser a morte, realizando a profecia de Tirésias. Essa espécie de absoluto que não se sustenta no mundo da aparência. A morte do herói é o castigo por essa coincidência entre o teor de verdade e o factual. Como a água (da aquarela) na relação com o fogo, o sem-expressão entra em jogo (Spiel) com a aparência, na medida em que refreia essa queda, esse desaparecer por desvelar a "totalidade absoluta", "falsa e enganosa" que ainda sobreviveria na "aparência bela como herança do caos" ${ }^{18}$. Nesse esteio, o ato de cobrir o almoço vincularia a esse encobrir o objeto, a obra de arte, numa tentativa de restaurar o véu sobre o objeto, e daí ser possível enxergar alguma beleza.

\section{A PASSAGEM: ECO E NARCISO ${ }^{19}$}

Narciso é um jovem, filho de Rei e Ninfa, que é amado por homens e mulheres, devido sua beleza, maior que as dos deuses eternos, nascida da violência. Contudo, é um ser jamais tocado, devido sua arrogância, em mesmo grau. Pelo desprezo desferido aos seus amantes, só consegue apaixonar-se por si, único digno de seu amor. Eco, ninfa eloquente que engana Juno para que as ninfas que se deitam com seu marido possam fugir da ira dessa deusa, é amaldiçoada a eternamente repetir as últimas palavras das frases dos outros. Ela não pode falar antes dos outros. A ninfa se apaixona por Narciso, que arrebatado por sua imagem, pergunta-lhe angustiado por que foge de seu toque. Eco, que próxima ao rio, onde se tornara pedra permanecendo somente sua voz - após ser rejeitada por Narciso, repete as palavras dele e o ilude, de certa forma, de que há resposta do reflexo amado - reflexo que ele sabe ser reflexo. $\mathrm{O}$ belo e angustiado Narciso morre e no lugar onde se derramou seu sangue, nascem flores - os narcisos.

Narciso é aquele que não encontra identificação com o outro, e lhe é totalmente alheio, tendo a si como unidade totalizante do mundo, a partir e para o qual nada mais é relevante, e Eco é aquela que somente existe no outro, pela expressão do outro, na medida em que é incapaz de expressar-se e, portanto, tornar-se um "sujeito". Eles são os opostos complementares,

\footnotetext{
${ }^{18}$ Idem, p. 92.

${ }^{19}$ CARVALHO, Raimundo N. B. 2010.
}

DIALEKTIKÉ, v. 1, novembro 2014, p. 66-80

Artigo submetido em setembro/2014 e aceito em outubro/2014 
entretanto, fadados ao sofrimento e morte. Narciso, pior, ainda padece de seu mal após a morte. Um é o egocêntrico que não reconhece uma comunidade e não se reconhece como parte dela. A outra seria uma espécie de alteridade plena, nascida de uma maldição, que anulada perante o outro, é incapaz de expressar seu sofrimento, criando uma ilusão, na mesma medida da ilusão de Narciso e seu reflexo. Eco repete as últimas frases de Narciso, consolidando a previsão de Tirésias. Aquele que é perpetuadamente a expressão do Outro é também a causa da morte do Eu narcísico. Eco ecoa o "eu” como a sentença de morte. Mesmo que haja uma liberdade em escolher o que expressar, ela continua sendo a expressão última do outro, outro que nesse caso é o cego Narciso, que só pesa-se com seu “eu”, mesmo quando reconhece a pobreza disso.

Entre ambos, ocorre uma afinidade eletiva ${ }^{20}$, na medida em que são colocados em contato, constituindo-se, porém, uma espécie de impossibilidade de contato, na medida em que Narciso é repelente da alteridade por excelência, enquanto Eco é a imagem absolutamente dessa alteridade. A afinidade deles surge dos extremos, criando um vínculo demasiadamente íntimo. Uma afinidade instável, que terá como resultado a morte de ambos. Eco elege Narciso como o amado, a alteridade absolutamente elege o individualista absolutamente, que somente por uma ilusão é atraído àquela. Ele decide seguir a morte, mesmo sabendo que se trata de uma ilusão, de que se trata de si mesmo - de quem deseja afastar-se, apartar-se, mas não consegue se livrar do ardor do desejo. Nessa eleição que se realiza entre ambos, a morte é o resultado, é a destruição como princípio decisivo. A passagem entre Pontos Gráficos Nodais e Farnel engendra-se no mesmo campo, na afinidade em que uma se apresenta como alteridade nascida do fragmento e a outra como o narcísico que se fecha em si, no encontro com o sem-expressão. Virtualmente, ambas condizem com a relação Eco-Narciso, mas já não ocorrem absolutamente. Dão-se fragmentariamente - quer dizer, numa escala microscópica da vivência do artista e da obra de arte -, a partir do princípio de destruição nascida da pobreza das experiências.

Todo o projeto da modernidade é, em larga medida, a concretização desse mito: a perpetuação do "eu", como centro do mundo, como centro valorizador do mundo. Contudo, isso, como bem se mostrou, foi também a sentença de morte desse projeto. Um projeto narcísico, voltado para si mesmo, incapaz de olhar para o lado, arrogante em mesmo grau, por quem se apaixona o Eco, que, por uma maldição, opera a repetição das palavras proferidas à Ilusão, que lhe retornam para que ela, incapaz de reconhecer a realidade e a ficção, encontre a morte. A arte, durante um bom tempo, sucumbiu a essa estratégia, e somente a duras penas,

${ }^{20}$ BENJAMIN, 2009, p.103.

DIALEKTIKÉ, v. 1, novembro 2014, p. 66-80

Artigo submetido em setembro/2014 e aceito em outubro/2014 
livra-se, agora, dessa maldição, desse mito. Todavia, isso só acontece com uma espécie de expiação, na medida em que a angústia e o sofrimento causado pelas ideologias pesaram em seus ombros como cadáveres, e encharcaram seus mantos brilhantes e seus muros de marfim com sangue, transformando-se numa viscosidade que busca agregar-se ao indivíduo, sendo difícil de apartar-se. A arte contemporânea, ou das pós-modernidades, procura responder, em algum grau, a esse peso, ora tentando refletir sobre o papel de modo a não recair no mesmo engano - um exercício de alteridade, poderíamos dizer -, ora aceitando o papel de desengordurador, "limpando" esses ambientes, trazendo-os a tona para a rememoração do papel da arte e da sociedade ao lembrar todos os que perderam suas vidas nas catástrofes.

\section{REFERÊNCIAS}

AGAMBEN, Giorgio. O homem sem conteúdo. Belo Horizonte: Autêntica, 2012.

BENJAMIN, Walter. Ensaios Reunidos: escritos sobre Goethe. São Paulo: Duas cidades; Editora 34, 2009.

\footnotetext{
Sobre arte, técnica, linguagem e política. Lisboa: Relógio D’água, 1992.

Origem do drama trágico alemão. Belo Horizonte: Autêntica, 2011.
}

CARVALHO, Raimundo N. B. Metamorfoses em tradução. 2010. 158 p. Relatório Final (Pós-doutoramento em Letras Clássicas e Vernáculas) - USP, São Paulo.

CAUQUELIN, Anne. A arte contemporânea. Porto: RésEditora, s/a.

GAGNEIN, Jeane Marie. Documentos de cultura /documentos de barbárie. Disponível em< http://pepsic.bvsalud.org/pdf/ide/v31n46/v31n46a14.pdf> Acesso: 31 mai 2012.

LUKÁCS, Georg. A Teoria do Romance: um ensaio histórico-filosófico sobre as formas da grande épica. 3 reimp. São Paulo: Editora Duas Cidades, Editora 34, 2007.

MACIEL, Artur de S. Pontos Gráficos Nodais em Fluxos da cidade do Natal. 2011. 77 p. Monografia (Poéticas Visuais) - UFRN, Natal.

MARTINS, Liana Carreira. "Do Azul ao Branco": Mallarmé e as construções da crise. Dissertação. Rio de Janeiro: UFRJ, 2011. 